\title{
Effect of platelet rich-fibrin on alveolar osteitis incidence following surgical removal of impacted mandibular third molars: A comparative study
}

\author{
Ali S. Abdul-Kareem, B.D.S ${ }^{1}$ \\ Ali H. Al-Hussaini, B.D.S., M.Sc. ${ }^{2}$
}

\begin{abstract}
Background: Postoperative morbidity after extraction of the impacted mandibular third molar (IMTM) is inevitable. One of the most common postoperative complication is alveolar osteitis (AO) which is a painful non healed socket. Many researches were attempted to prevent the occurrence of $A O$ by introducing and applying a new materials inside the extraction socket. Platelet rich fibrin (PRF) is a biological complex fibrin matrix where autologous platelets and leucocytes are present, used to enhance tissue healing process and reduce the early adverse effects of the inflammation.
\end{abstract}

Aims: To evaluate the effect of PRF on the incidence of AO. Also to assess PRF effect on pain, swelling, and trismus following the surgical removal of IMTM and compare it with the control group.

Materials and methods: This clinical prospective study was conducted from October 2016 to October 2017 at the Department of Oral \& Maxillofacial Surgery, College of dentistry/University of Baghdad; and Al-Sadr Specialized Health Center. A total number of 50 IMTMs were surgically removed from 45 patients who met the inclusion criteria (21 males and 24 females) with age ranged from 16-41 years. The cases were divided into two groups: a study group ( 25 cases) where PRF were placed inside the extraction socket and control group (25 cases) where traditional surgery were performed. AO, trismus and swelling were assessed at the $2^{\text {nd }}$ and $7^{\text {th }}$ postoperative day. Pain scored by numeric rating scale daily by the patients.

Results: The study showed that age, gender, side of impaction, oral hygiene condition, impacted tooth classification, surgical difficulty, and the time of procedure in both control and study groups had nearly similar distribution with nonsignificant difference. At the $1^{\text {st }}$ follow up period: Trismus (P-value $\left.=0.834\right)$ and Swelling $(P$-value $=0.592)$ were nonsignificant between the two groups. AO had overall incidence of $4 \%$ occurred only in the control group, while the PRF group had no occurrence (0\%), but the difference was statistically non significant. Postoperative pain had no significance difference in both groups. At the $2^{\text {nd }}$ follow up period there was no significant difference regarding trismus, swelling, and incidence of AO between both groups.

Conclusion: Local application of PRF can reduce the incidence of AO but not to a significant level. PRF had no effect concerning postoperative pain, swelling, and trismus.

Keywords: Platelet rich fibrin, alveolar Osteitis, impacted mandibular third molar. (Received: 15/1/2018; Accepted: 30/2/2018)

\section{INTRODUCTION}

Impacted teeth are most frequently found among mandibular third molars and may lead to pericoronitis, periodontitis, damage to neighboring teeth, crowding of the anterior teeth, and temporomandibular symptoms. Furthermore, the impacted teeth is a potential origin of odontogenic cysts and tumors. Therefore, impacted mandibular third molars (IMTMs) are usually extracted ${ }^{[1]}$.

New statistics submits that $72.2 \%$ of the world population has at least one impacted tooth (often lower third molar). Pain, edema, trismus, bleeding and alveolar osteitis (AO) are the most common complications following the surgical extraction of impacted teeth. Pain reaches peak levels of 6 to 12 hours and swelling 2 to 3 days postoperatively. Trismus is a temporary muscle spasm and subside gradually after the surgery ${ }^{[2]}$.

1. Master Student, Department of Oral and maxillofacial Surgery, College of Dentistry, University of Baghdad.

2. Assisstant Professor, Department of Oral and Maxillofacial Surgery, College of Dentistry, University of Baghdad.
Dry socket or AO is a common postoperative complication usually associated with the extraction of IMTMs and defines as an intense pain within and around socket of the extracted tooth, had an onset between the $1^{\text {st }}$ and $3^{\text {rd }}$ day after the extraction with a complete or partial blood clot disintegration ${ }^{[3]}$. It is interruption in healing process that disturb the conversion of the mature blood clot into granulation tissue ${ }^{[3]}$. Several methods were used to control the immediate inflammatory response including secondary closure technique, window excision of the mucosa, use of drains, suture-less or single suture technique, administration of antibiotics, analgesic, corticosteroid, and by the application of low level laser therapy ${ }^{[4]}$.

Many researchers attempt to find a successful method for prevention of alveolar osteitis including local and systemic antibiotic, 
chlorhexidine rinse or gel, steroid, eugenol containing dressing, antifibrinolytic agent, low level laser therapy, biodegradable polymers, topical hemostatics, oxidized regenerated cellulose, and dextranomer granules ${ }^{[5]}$.

Platelet rich fibrin (PRF) is a biological autologous material obtained simply by centrifugation of the patient's own blood without anticoagulants. Its fibrin matrix encompasses platelets and leukocytes as well as a variety of cytokines and growth factors, and it was presented to accelerate soft tissue healing [6].

The effect of PRF on the postoperative inflammatory response (pain, swelling, and trismus) and on the $\mathrm{AO}$ incidence after its placement in the socket of surgically extracted IMTMs were evaluated in this research.

\section{MATERIALS AND METHODS}

This clinical prospective study was conducted from October 2016 to October 2017 at the Department of Oral \& Maxillofacial Surgery, College of dentistry/University of Baghdad; and Al-Sadr Specialized Health Center.

A total number of IMTMs 50 teeth were allocated in two groups, Study group (25 tooth) in which the impacted tooth was extracted and PRF was immediately applied in the socket and Control group (25 tooth) in which the impacted tooth was removed without application of PRF. Any patient age $\geq 15$ who had unilateral or bilateral unerupted, partially, or fully IMTMs which indicated for surgical extraction were included in this study. The exclusion criteria was:

1. Acute pericoronitis or IMTM associated with pathologies.

2. Smoker and pregnant patients.

3. Medically compromised patients and patients who take chemotherapy or radiotherapy in the last year.

\section{Preoperative assessment}

Medical and dental history were documented and clinical examination (extraoral \& intraoral) were performed for each patient. Oral hygiene condition was assessed by the Greene and Vermillion method as mentioned by Alkhadra ${ }^{[7]}$, were scored as follow:

- Good oral hygiene $=1$

- Fair oral hygiene $=2$

- Bad oral hygiene = 3
Preoperative orthopantomography (OPG) was taken for the patient to assess the location and configuration of impacted third molar, adjacent tooth, mandibular canal, and surrounding bone. The class and depth of the impacted tooth were documented according to Pell and Gregory's classification. While angulation were classified according to Quek, et al. (2003) method ${ }^{[8]}$ by drawing lines to represent the intersected longitudinal axes of the second and third molars then measuring the angle formed between them:

- Vertical impaction: $10^{\circ}$ to $-10^{\circ}$.

- Mesioangular impaction: $11^{\circ}$ to $79^{\circ}$.

- Horizontal impaction: $80^{\circ}$ to $100^{\circ}$.

- Distoangular impaction: - $11^{\circ}$ to $-79^{\circ}$.

- Others: $101^{\circ}$ to $-80^{\circ}$.

\section{Scoring the surgical difficulty}

The difficulty of extraction were divided into 3 categories: slightly difficult, moderately difficult, and very difficult according to Pederson index ${ }^{[9]}$ (Table 1).

Table 1 Pederson's difficulty index.

\begin{tabular}{|cc|}
\hline Criteria & Value \\
\hline Angulation & \\
Mesioangular & 1 \\
Horizontal & 2 \\
Vertical & 3 \\
Distoangular & 4 \\
& \\
Depth of IMTM & \\
Position A & 1 \\
Position B & 2 \\
Position C & 3 \\
& \\
Class of IMTM & 1 \\
Class I & 2 \\
Class II & 3 \\
Class III & \\
& \\
Index = sum of angulation, depth, and class & \\
& Total \\
Slightly difficult & $3-4$ \\
Moderately difficult & $5-6$ \\
Very difficult & -10 \\
& \\
\hline
\end{tabular}

\section{Surgical procedure}

The patients was received information about the proposed surgical procedure and its risk, so they signed in an informed consent to proceed with the recommended treatment. The surgeries were performed under local anesthesia (3 
cartridges of $2 \%$ Lidocaine with 1:80,000 adrenaline) by the same operator.

Incision for horizontal mucoperiosteal flap was started just distolateral to the impacted tooth and continue buccally around the gingival margins till it reach the mesial side of the $2^{\text {nd }}$ molar where a vertical buccal releasing incision were performed (Bayonet flap).

The mucoperiosteal flap was reflected and the bone was removed to expose the cervical line of the tooth using round or fissure burs and a low speed/ high torque surgical straight handpiece. If required, the tooth was sectioned into pieces to facilitate delivery from the socket. After tooth removal, the socket was irrigated with $10 \mathrm{~mL}$ of normal saline then suturing with $3 / 0$ black silk suture in control group.

\section{PRF preparation and application}

In the study group, after intentionally making the tooth subluxated and before elevate it completely from the socket, blood aspiration to prepare the PRF began. Ten $\mathrm{mL}$ of autogenous venous blood was collected from an appropriate vein in the antecubital fossa.

The obtained blood was immediately transferred to a plain $10 \mathrm{~mL}$ blood collecting tube and centrifuged at 3000 rounds per minute for 10 minutes. At the end of this process, the yellow shiny gelatinous part in the middle of the tube was the PRF (Fig.1).

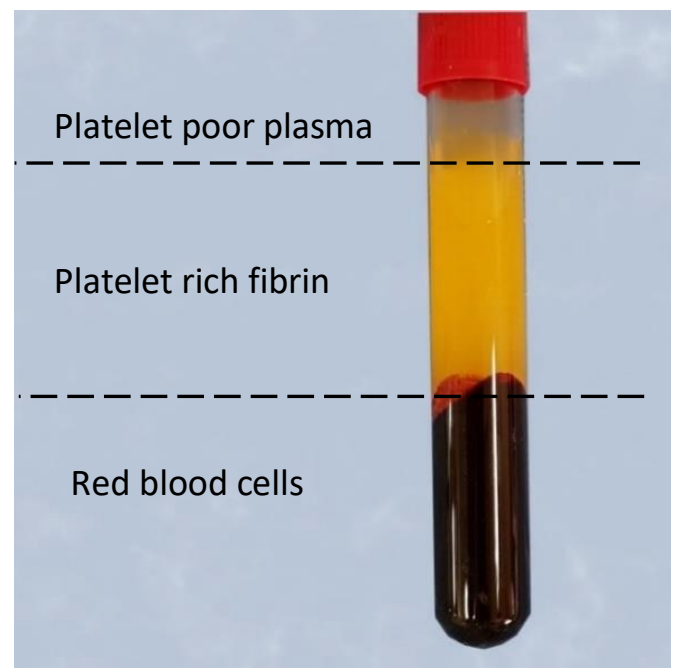

Figure 1: layers after blood centrifugation

Using tweezers gently the PRF were pulled out and placed in a sterile wet gauze mesh, scraping the bulk of RBC layer carefully by surgical scalpel leaving the buffy coat intact (Fig. 2)

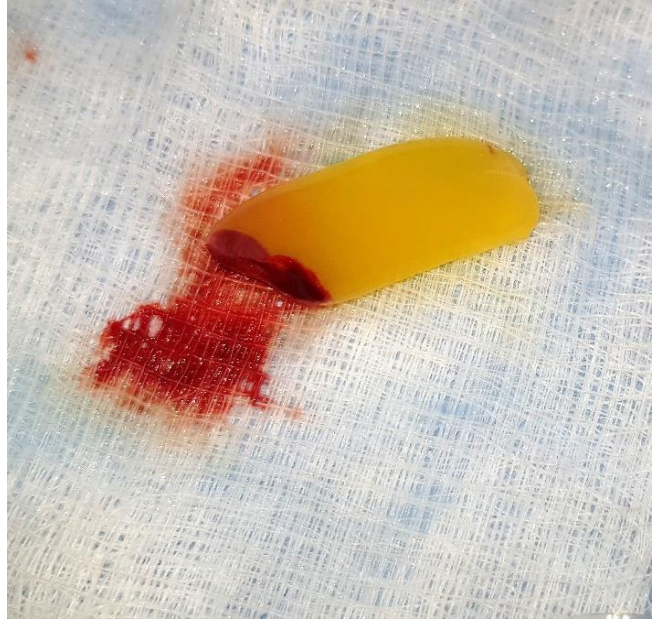

Figure 2: Platelet-rich fibrin

When the centrifuge rotation nearly reach its ending, the tooth or the root (if the crown was sectioned previously) was removed, the bone was smoothed /and the socket was irrigated with normal saline, place the PRF gently inside the socket, then suturing the flap (Fig. 3). The time of the operation was recorded from the incision to the end of suturing for each surgery.

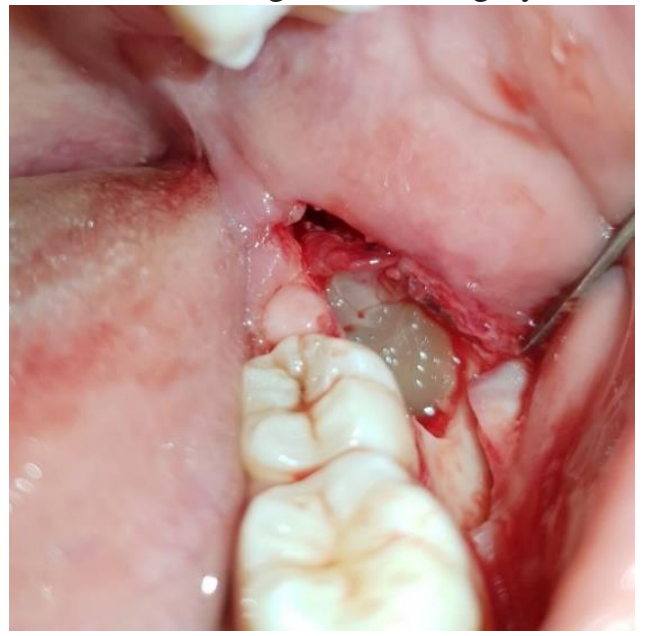

Figure 3: platelet-rich fibrin inside the socket

\section{Evaluation procedure}

Four variables were evaluated in this study: mouth opening, swelling, pain, and the incidence of AO. The follow up took place in the $3^{\text {rd }}$ and $8^{\text {th }}$ days. The surgical operation day was considered as the $1^{\text {st }}$ day.

The following terms were used:

$\mathrm{T}_{0}=$ the day of operation (preoperative).

$\mathrm{T}_{1}=$ the second postoperative day.

$\mathrm{T}_{2}=$ the seventh postoperative day.

The degree of maximum mouth opening were recorded using a sliding caliber by measuring the distance from the incisal edges of the upper 
left to the lower left central incisor as the mouth opened to its limit.

The extent of the swelling was measured by swelling measurement device (SMD). The idea was to measure the distance of the skin that will protrude postoperatively in 16 different points around the angle of the mandible in $\mathrm{mm}$.

SMD consist of a modified disposable impression tray which could be detached and fixed easily to the device by a nuts and built-in bolts and a two perforated rectangular plates facing the angles of the mandible extraorally. Each plate contain a 20 parallel holes (5 columns and 4 rows). These holes has a diameter that fit a calibrated straight cylinder bar (Fig. 4).

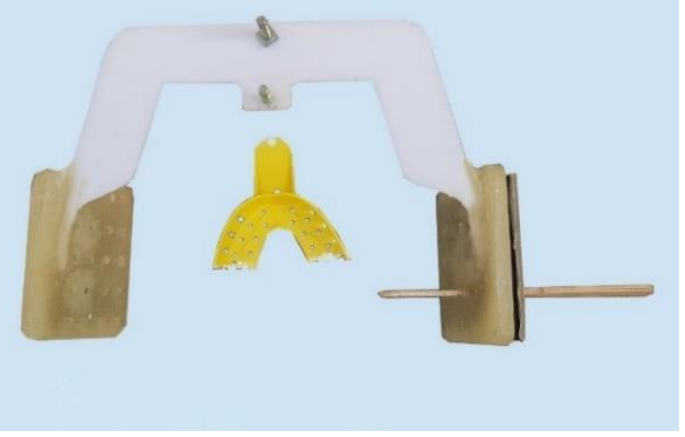

Figure 4: Swelling measurement device The technique of measurement was: Making an impression for the upper teeth by modified disposable tray after checking its fitness in the patient mouth, removal of the tray from the patient's mouth when the impression material was sat, fixing the tray to the SMD. Now, reinserting the SMD with its fixed tray again in the patient's mouth while the lower jaw in rest position for making the measurement. The upper impression work as a reference point for the SMD and exactly take the same position any time it inserted inside the patient's mouth.

The distance between the inner surface of the perforated plate and the skin was recorded, this done by a calibrated straight cylinder bar which enter to the holes of the plate and move medially till it touch the skin, this process was repeated in a selected 16 holes in the plate.

The mean measurement was calculated before the surgery at $\mathrm{T} 0$ as a baseline and similar measurements were carried out at $\mathrm{T} 1$ and $\mathrm{T} 2$ (Fig. 5).

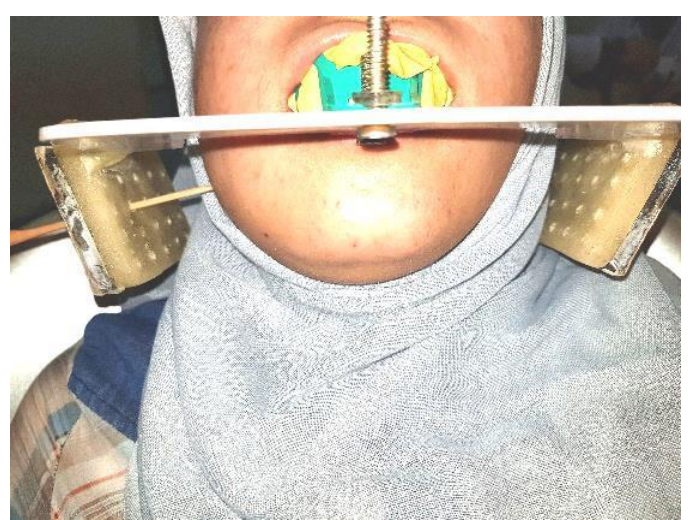

Figure 5: Using the swelling measurement device at $1^{\text {st }}$ follow up period.

The pain was scored by the patient using numeric rating scale (NRS), where the number 0 represent no pain while number 10 represent the worst imaginable pain. The time to utilize the pain chart was determined by the operator at $10 \mathrm{pm}$ and the patients were informed to restrict at that time daily for 7 days.

The diagnosis of $\mathrm{AO}$ was done by an expert surgeon other than the operator to reduce the bias. The socket should had partial or complete blood clot loss and a pain score in NRS $(\geq 6)$ in the extraction site at the time of checking to consider it as $\mathrm{AO}$ with or without foul odor.

The patients were instructed to return if they experienced any persistent and progressive pain between follow-up visits. The cases of AO were treated by normal saline irrigation of the socket and packing it with Alvogel (India). Antibiotic and analgesic were also prescribed.

\section{Statistical analysis}

SPSS version 14.0 were used in order to analyze and assess the results of this study utilizing the following inferential data analysis: Two independent-samples t-test, homogeneityof-variance, matched paired-samples t-test, and repeated measures analyzes groups of related dependent variables.

\section{RESULTS}

Study sample comprised 45 patients (21 males \& 24 females) aged 16-41 years with 50 IMTMs. 25 IMTMs regarded as control group and the remaining 25 IMTMs as study group.

The results show that distribution of age, gender, side of impaction, oral hygiene condition, and the IMTMs classification (angulations, depths, and classes) between both groups were nearly similar and had non statistical significant difference. Furthermore, the age group (20-24 years) and 
females accounted with the vast majority of attendance $(40 \%)$ and $(56 \%)$ respectively. Also, mesioangular (52\%) and position A (58\%) had the higher prevalence in IMTMs classification while class I and class II had equal distribution (48\%). The results displayed that vast majority of the studied sample had a moderately difficult surgical extraction according to Pederson index (Fig. 6).

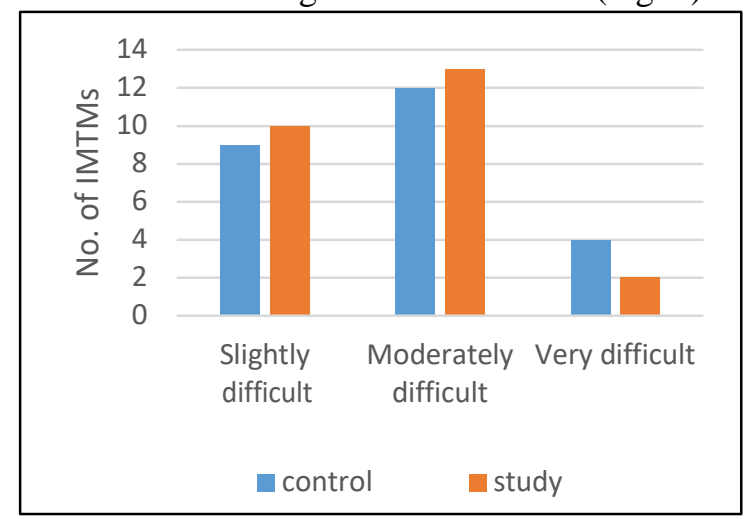

Figure 6: Distribution of impacted teeth according to Pederson difficulty index

Adding to that no significant difference were found which indicate similar distribution of the surgical difficulties between the control and study groups.

The mean time spent for surgical operation were listed in Table (2) which had a non- significant difference between both groups.

Table 2: Mean of surgical operation time.

\begin{tabular}{|c|c|c|c|c|c|}
\hline \multirow{2}{*}{ Group } & \multirow{2}{*}{$\begin{array}{l}\text { Mean } \\
\text { (Min.) }\end{array}$} & \multirow{2}{*}{ SD } & \multirow{2}{*}{ SE } & \multicolumn{2}{|c|}{ t-test } \\
\hline & & & & $\mathbf{t}$ & Sig. \\
\hline Control & 36.52 & 13.47 & 2.69 & \multirow{2}{*}{-1.643} & 0.107 \\
\hline Study & 44.76 & 21.14 & 4.23 & & NS \\
\hline
\end{tabular}

SD: standard deviation. SE: standard error. NS: non significant

\section{Trimus and swelling}

The degree of mouth opening and the extent of swelling were measured at $T_{0}, T_{1}$, and $T_{2}$; however, there were no statistically significant differences between the groups (Table 3). The amount of swelling were recorded by SMD.

\section{Pain}

The results display that studied samples had mostly a parallel behavior concerning pain parameter throughout 7 postoperative days as it scored by the patient daily using NRS, which reduced on passing of times. Besides that, no significant differences were obtained between the study and control group at each days (Table 4).
Table 3: The mouth opening and swelling between both groups.

\begin{tabular}{ccccc} 
Parameter & $\begin{array}{c}\text { Study } \\
\text { Mean (SD) }\end{array}$ & $\begin{array}{c}\text { Control } \\
\text { Mean } \\
\text { (SD) }\end{array}$ & $\begin{array}{c}\text { P } \\
\text { value }\end{array}$ \\
$\begin{array}{ccccc}\text { Mouth } \\
\text { opening } \\
(\mathrm{mm})\end{array}$ & $\mathrm{T}_{0}$ & $49.9(6.9)$ & $50.7(7.4)$ & $\begin{array}{c}0.697 \\
\mathbf{N S}\end{array}$ \\
& $\mathrm{T}_{1}$ & $39.5(10.2)$ & $39(8.4)$ & $\begin{array}{c}0.834 \\
\mathbf{N S}\end{array}$ \\
& $\mathrm{T}_{2}$ & $46.5(7.6)$ & $47.4(8.1)$ & $\begin{array}{c}0.710 \\
\mathbf{N S}\end{array}$ \\
& $\mathrm{T}_{0}$ & $34.8(7.6)$ & $34.7(5.8)$ & $\begin{array}{c}0.972 \\
\mathbf{N S}\end{array}$ \\
$\begin{array}{c}\text { Swelling } \\
(\mathrm{mm})\end{array}$ & $\mathrm{T}_{1}$ & $32.9(8.4)$ & $31.6(5.3)$ & $\begin{array}{c}0.592 \\
\mathbf{N S}\end{array}$ \\
& $\mathrm{T}_{2}$ & $34.7(7.9)$ & $34.3(5.7)$ & $\begin{array}{c}0.839 \\
\mathbf{N S}\end{array}$ \\
\hline
\end{tabular}

SD: standard deviation. NS: non significant

Table 4: Pain score between both groups using numeric rating scale.

\begin{tabular}{|cccc|}
\hline Days & $\begin{array}{c}\text { Study } \\
\text { Mean }\end{array}$ & $\begin{array}{c}\text { Control } \\
\text { Mean }\end{array}$ & P value \\
\hline Day 1 & 5.88 & 5.16 & 0.380 NS \\
\hline Day 2 & 3.92 & 4.08 & 0.843 NS \\
\hline Day 3 & 3.12 & 2.56 & 0.445 NS \\
\hline Day 4 & 1.76 & 1.96 & 0.676 NS \\
\hline Day 5 & 1.68 & 1.32 & 0.476 NS \\
\hline Day 6 & 1.40 & 1.08 & 0.584 NS \\
\hline Day 7 & 0.64 & 0.72 & 0.809 NS \\
\hline
\end{tabular}

NS: non significant

\section{Alveolar osteitis}

The overall incidence of $\mathrm{AO}$ in this study was (4\%) as shown by the results and were recognized

PRF group, while no occurrence of AO were detected at $\mathrm{T} 2$ in both groups, in addition to that no significant difference at each period were detected between the study and control groups (Table 5).

Table 5: Incidence of alveolar osteitis.

\begin{tabular}{c|c|c|c|c|c} 
T & AO & Study & Control & Total & $\begin{array}{c}\text { P } \\
\text { value }\end{array}$ \\
\hline & + & 0 & 2 & 2 & \\
\hline $\mathrm{T}_{1}$ & & $0 \%$ & $8 \%$ & $4 \%$ & 0.245 \\
& - & 25 & 23 & 48 & $\mathbf{N S}$ \\
& & $100 \%$ & $92 \%$ & $96 \%$ & \\
\hline & + & 0 & 0 & 0 & \\
$\mathrm{~T}_{2}$ & + & $0 \%$ & $0 \%$ & $0 \%$ & 1.000 \\
& - & 25 & 25 & 50 & $\mathbf{N S}$ \\
& & $100 \%$ & $100 \%$ & $100 \%$ & \\
\hline
\end{tabular}

T: times. AO: alveolar osteitis. (+) presence. (-) absence. NS: non significant

\section{DISCUSSION}

Surgical removal of impacted mandibular third molars (IMTMs) are always associated with soft 
and hard tissue trauma, so postoperative morbidity can't be eliminated completely. Surgeons in oral and maxillofacial continuously pursue a new materials or a modified surgical technique to improve outcomes. Platelet-rich fibrin (PRF) was utilized in various surgeries as a bioactive material which is obtained from the patient's own blood to enhance soft and hard tissues healing.

In the present study, the mean preoperative $\left(\mathrm{T}_{0}\right)$ mouth opening in the control group was $50.72 \pm 7.48 \mathrm{~mm}$ and in the PRF group was

$49.92 \pm 6.96 \mathrm{~mm}$ (Table 3 ). The P-value was 0.834 in $T_{1}$ and 0.71 in $T_{2}$ between both groups, and this showed that PRF application had no effect regarding postoperative trismus. These finding is supported by other studies ${ }^{[11,12]}$ who concluded a non-significant difference regarding mouth opening postsurgically. Other study in contrast had stated a significant difference on the $1^{\text {st }}$ postoperative day ${ }^{[13]}$.

The surgical extraction of IMTMs may cause limitation in mouth opening as a result of either inflammation involving the muscles of mastication or direct trauma to the $\mathrm{TMJ}^{[14]}$. The etiology of trismus may be sited away from the local effect of the PRF, so the muscles of mastication and the TMJ located far from the local benefit of PRF and its releasing factors.

The maximum extent of swelling in the current study were observed at $\mathrm{T}_{1}$, and in comparison between both groups at $T_{1}$ and $T_{2}$ the result showed less amount of swelling in the study group at each periods but it doesn't reach to a statistical significant level. In support to this result other clinical studies concluded a statistically no significant difference between study and control group ${ }^{[12,15,16,17]}$. On the other hand, other clinical studies were reported a significant difference regarding swelling reduction in the PRF group ${ }^{[13,18]}$.

Three cytokines TNF- $\alpha$, IL-1, and IL-6 play a major role in acute inflammation as they increase blood vessels permeability and this in turn increase the osmotic pressure of the interstitial fluid, the result is exudate edema ${ }^{[19]}$.

PRF had a high concentrations of antiinflammatory cytokines IL-4, but also showed identical high serological concentrations of proinflammatory mediators, such as IL- $1 \beta$, IL6 and TNF- $\alpha{ }^{[20]}$. This balance may explain the non-effectiveness of PRF to reduce postoperative swelling into a significant level. In the present study, the pain was gradually reduced in a significant difference till $6^{\text {th }}$ day in the control group, and to $5^{\text {th }}$ day in the study group. In the remaining days the pain was decreased in a non-significant rate.

In comparison of pain between the study samples, this study found no significant difference at 10 pm for each day. In accordance to this, studies which evaluate the pain by visual analogue scale and showed a statistically non-significant differences between PRF and non PRF groups. However, in a bilaterally IMTMs study by Kumar et al. (2016) recorded a significantly pain reduction in experimental group compare to the control [23].

This controversies in pain assessment may be belong to the patients' pain tolerance Kemp et al. (2012) concluded that visual analogue scale appears to be unreliable for obtaining objective information about the experiential dimensions of pain ${ }^{[24]}$. Inflammatory mediators (e.g. bradykinin, histamine, 5-hydroxytryptamine) which are released after tissue injury have known as endogenous pain-inducing substances, which are able to sensitise or excite the peripheral terminals of nociceptive neurons and caused an inflammatory pain ${ }^{[25]}$. In our knowledge, no clinical study was reported that PRF application prevent the releasing of pain inducing mediator after the surgery, and this may be the reason behind the uneffectivness of PRF on the postoperative inflammatory pain. As shown by the result of this study, the total incidence of $\mathrm{AO}$ was 2 cases (4\%) among 50 cases only occur at $T_{1}$ in control group. The low incidence of $\mathrm{AO}$ may be attributed to the limited sample size and to the avoidance of some of AO risk factors such as, the operator performed the surgery with minimum trauma as possible, aseptic surgical field, exclusion of medically compromised and smoker patients, and no attendance of patients used oral contraceptives drug. Supporting that, there is a relationship between elevated surgical difficulty and AO, since trauma causes delayed healing through compression of the thin compact alveolar bone of the socket, thrombosis in underlying vessels, reduced 
tissue resistance that predisposes the wound to infection ${ }^{[26]}$.

In the study group where the PRF applied, there was no occurrence $(0 \%)$ of AO compared to two cases in the control group, but it doesn't reached to a statistical significant level between groups. This result come in agreement with Asutay et al. (2016) who found in a clinical study a non-significant result between of PRF and control groups ${ }^{[12]}$. In contrast, other clinical studies achieved a significant reduction of $\mathrm{AO}$ following the application PRF with a ranges of incidence $0-2.6 \%$ in study group and $9.5-16 \%$ in control group ${ }^{[1,27,28]}$.

The absence of the development of AO in the socket which were filled with PRF may be accounted to the PRF properties as reported by Choukroun et al. (2006) who concluded that fibrin matrix of the PRF guides the epithelial cells and fibroblasts migration and increase their metabolism when cover the injured tissues, also PRF consider as biomaterial encouraging neovascularization, and it is a natural support to immunity ${ }^{[29]}$.

This study concluded that local application of PRF can reduce the incidence of AO but not to a significant level. PRF had no effect concerning postoperative pain, swelling, and trismus. The limitation of this study were: small sample size and non-randomized method.

\section{REFERENCES}

1. He Y, Chen J, Huang Y, Pan Q, Nie M. Local application of platelet-rich fibrin during lower third molar extraction improves treatment outcomes. J Oral Maxillofac Surg 2017; 75(12): 2497-2506.

2. Kasapoğlu Ç, Brkić A, Gürkan-Köseoğlu B, KoçakBerberoğlu H. Complications following surgery of impacted teeth and their management. In: MHK Motamedi, ed., A textbook of advanced oral and maxillofacial surgery. Rijeka: InTech; 2013. p. 1-25.

3. Tarakji B, Saleh LA, Umair A, Azzeghaiby SN, Hanouneh S. Systemic review of dry socket: aetiology, treatment, and prevention. J Clin Diagn Res 2015; 9(4): 10-13.

4. Osunde O, Adebola R, Omeje U. Management of inflammatory complications in third molar surgery: A review of the literature. Afr Health Sci 2011; 11(3): 530-537.

5. Gowda GG, Viswanath D, Kumar M, Umashankar DN. Dry Socket (Alveolar Osteitis): Incidence, Pathogenesis, Prevention and Management. Med Radiol 2013; 25(3): 196-199.
6. Miron RJ. Zucchelli G, Pikos MA, Salama M, Lee S, Guillemette V, Fujioka-Kobayashi M, Bishara M, Zhang Y, Wang HL, Chandad F. Use of platelet-rich fibrin in regenerative dentistry: a systematic review. Clin Oral Investig 2017; 21(6): 1-15.

7. Alkhadra T. Prevalence of Dental Caries and Oral Hygiene Status among Juvenile Prisoners in the Kingdom of Saudi Arabia. The journal of contemporary dental practice 2017; 18(11): 991-5.

8. Quek SL, Tay CK, Tay KH, Toh SL, Lim KC. Pattern of third molar impaction in a Singapore Chinese population: a retrospective radiographic survey. Int $\mathbf{J}$ Oral Maxillofacial Surg 2003; 32(5): 548-552.

9. Lee JY, Do HS, Lim JH, Jang HS, Rim JS, Kwon JJ, Lee ES. Correlation of antibiotic prophylaxis and difficulty of extraction with postoperative inflammatory complications in the lower third molar surgery. Br J Oral Maxillofac Surg 2014; 52(1): 5457.

10. Arkkelin, D. Using SPSS to understand research and data analysis. Psychology Curricular Materials 2014. P.1-194.

11. He Y, Chen J, Huang Y, Pan Q, Nie M. Local application of platelet-rich fibrin during lower third molar extraction improves treatment outcomes. J Oral Maxillofac Surg 2017; 75(12): 2497-2506.

12. Asutay F, Yolcu Ü, Geçör O, Acar AH, Öztürk SA, Malkoç S. An evaluation of effects of platelet-rich-fibrin on postoperative morbidities after lower third molar surgery. Niger J Clin Pract 2016; 10: 1119-3077.

13. Kumar N, Prasad K, Ramanujam L, Ranganath K, Dexith J, Chauhan A. Evaluation of treatment outcome after impacted mandibular third molar surgery with the use of autologous platelet-rich fibrin: a randomized controlled clinical study. J Oral Maxillofac Surg 2015; 73(6): 1042-1049.

14. Kasapoğlu Ç, Brkić A, Gürkan-Köseoğlu B, KoçakBerberoğlu H. Complications following surgery of impacted teeth and their management. In: Motamedi MHK, ed., A textbook of advanced oral and maxillofacial surgery. Rijeka: InTech; 2013: 1-25.

15. Bilginaylar K, Uyanik LO. Evaluation of the effects of platelet-rich fibrin and piezosurgery on outcomes after removal of impacted mandibular third molars. Br J Oral Maxillofac Surg 2016; 54(6): 629-633.

16. Esen A, Menziletoğlua D, Iş1k BK. Effect of plateletrich fibrin in reducing postoperative complications after impacted third molar surgery: a prospective, randomized controlled clinical trial. Acta Odontol Turc 2017; 34(2), pp. 46-49.

17. Guilşen U, Şentürk MF. Effect of platelet rich fibrin on edema and pain following third molar surgery: a split mouth control study. BMC Oral Health 2017; 17(1): 79-85.

18. Al Nashar A, Yakoob H, Alahmad MA, Dhafer YT, Khlil H. Clinical and radiographic outcomes of the use of Platelet-Rich Fibrin after impacted mandibular third molar surgery: a controlled prospective study. Int Dent J Students Res 2016; 4(1): 53-59.

19. Kumar V, Abbas AK, Aster JC. Robbins basic pathology, 9th ed. Philadelphia: Elsevier Health Sciences 2013: 48

20. Dohan DM, Choukroun J, Diss A, Dohan SL, Dohan AJ, Mouhyi J, Gogly B. Platelet-rich fibrin (PRF): a second-generation platelet concentrate. Part III: 
leucocyte activation: a new feature for platelet concentrates?. Oral Surg Oral Med Oral Pathol Oral Radiol Endod 2006; 101(3): e51-e55.

21. Singh A, Kohli M, Gupta N. Platelet rich fibrin: a novel approach for osseous regeneration. J Oral Maxillofac Surg 2012; 11(4): 430-434.

22. Ozgul O, Senses F, Er N, Tekin U, Tuz HH, Alkan A, Kocyigit ID, Atil F. Efficacy of platelet rich fibrin in the reduction of the pain and swelling after impacted third molar surgery: Randomized multicenter split-mouth clinical trial. Head Face Med 2015; 11(1): 37-42.

23. Kumar YR, Mohanty S, Verma M, Kaur RR, Bhatia P, Kumar VR, Chaudhary Z. Platelet-rich fibrin: the benefits. Br J Oral Maxillofac Surg 2016; 54(1): 5761

24. Kemp J, Despres O, Dufour A. Unreliability of the visual analog scale in experimental pain assessment: a sensitivity and evoked potentials study. Pain Physician 2012; 15(5): 693-699.

25. Linley JE, Rose K, Ooi L, Gamper N. Understanding inflammatory pain: ion channels contributing to acute and chronic nociception. Pflügers Archiv: Eur J Phy 2010; 459(5): 657-669.

26. Taberner-Vallverdú M, Sánchez-Garcés MÁ, GayEscoda C. Efficacy of different methods used for dry socket prevention and risk factor analysis: A systematic review. Med Oral Patol Oral Cir Bucal 2017; 22 (6): 750-758

27. Hoaglin DR, Lines GK. Prevention of localized osteitis in mandibular third-molar sites using plateletrich fibrin. Int J Dent 2013: e875380.

28. Al-Hamed FS, Tawfik MAM Abdelfadil E. Clinical effects of platelet-rich fibrin (PRF) following surgical extraction of lower third molar. Saudi J Dent Res 2016; 8(1): 19-25.

29. Choukroun J, Diss A, Simonpieri A, Girard MO, Schoeffler C, Dohan SL, Dohan AJ, Mouhyi J, Dohan DM. Platelet-rich fibrin (PRF): a secondgeneration platelet concentrate. Part IV: clinical effects on tissue healing. Oral Surg Oral Med Oral Pathol Oral Radiol Endod 2006; 101(3): 56-60.

\section{الخلاصة الغنة}

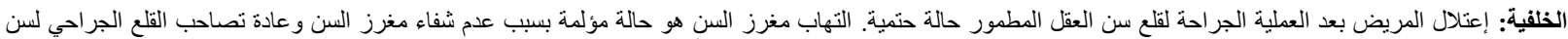

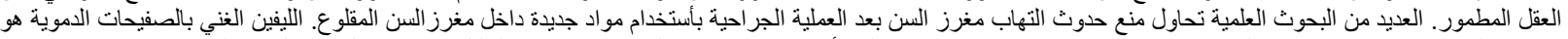

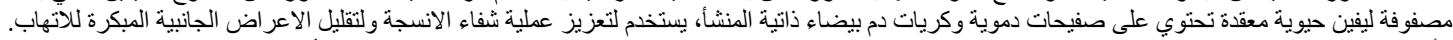

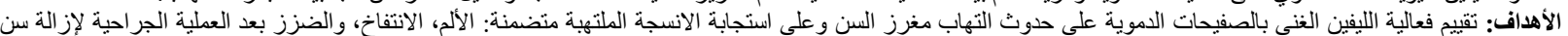

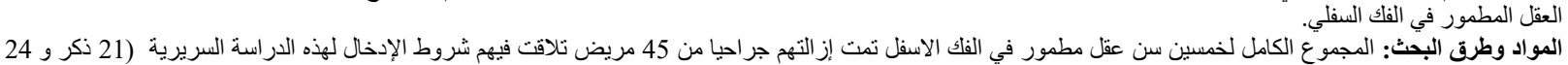

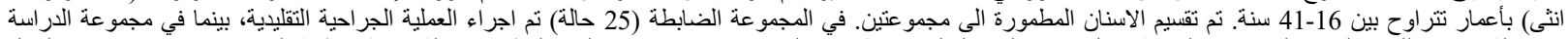

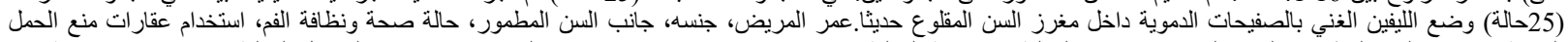

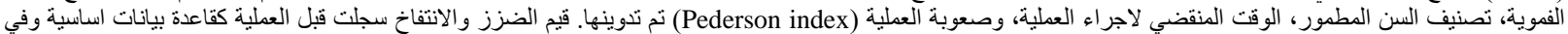

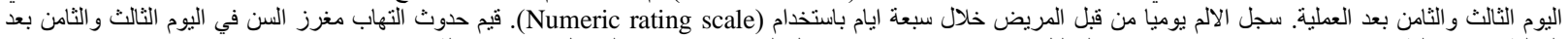

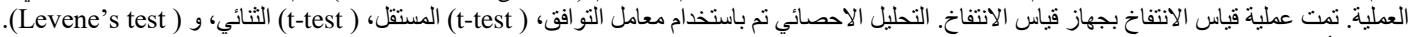

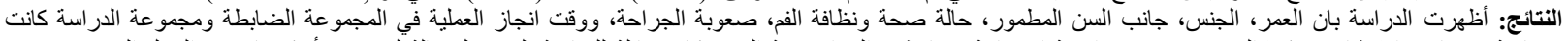

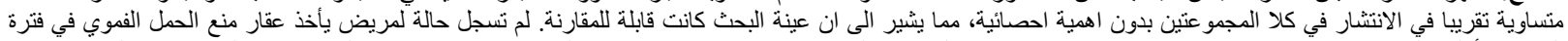

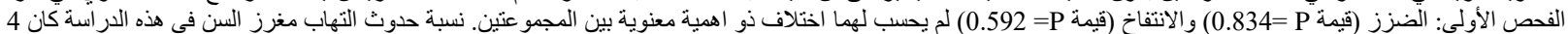

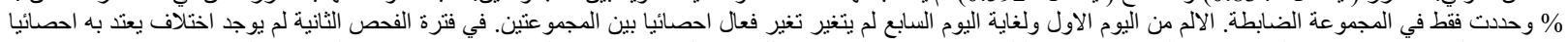

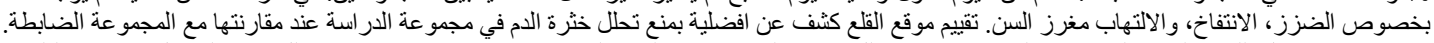

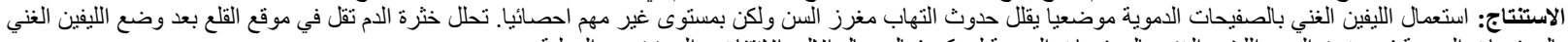

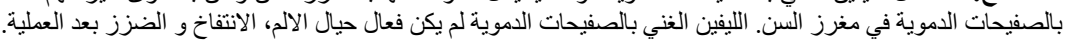

